\title{
APPLYING GEOBIA METHOD TO ANALYZE CLIMATE CHANGES ASSOCIATED TO ENERGY GENERATION - ANALYSIS ABOUT OIL EXPLORATION ONSHORE AT POTIGUAR BASIN
}

\author{
A. M. Alves ${ }^{a}$, V. E. Amaro ${ }^{\text {b }}$ \\ ${ }^{a}$ State University of Rio Grande do Norte, Student of the Graduate Program in Science and \\ Petroleum Engineering - agassiel@gmail.com \\ ${ }^{\mathrm{b}}$ Federal University of Rio Grande do Norte, GEOPRO Laboratory, Department of \\ Geology - amaro@ufrn.br
}

KEY WORDS: Geobia, Oil Explorations, Albedo, Reflectance, Climate Changes.

\begin{abstract}
:
This paper deals with the discussion of the analysis of remote sensing data on onshore oil exploration occurring in the Potiguar Basin, in the state boundaries of Rio Grande do Norte - Brazil, from the perspective of changes in albedo index, surface reflectance and surface temperature associated with to those aspects. The albedo is considered a significant variable in understanding the energy balance that makes up an important element of the analysis of global climate change. Through the use of remote sensing tools and GIS, based on surface reflectivity algorithms and surface temperature from GEObia (GEOgraphic-Object-Based Image Analysis) from the sequence - Pan-sharpened composite, Radiance with atmospheric correction, Reflectance with atmospheric correction, and Surface temperature with emissivity correction, used in scenes produced by OLI sensors (Operational Land Imager) and TIRS (Thermal Infrared Sensor) Landsat- 8 satellite, it was possible to determine the variations in surface reflectance and surface temperature, and compare them to index albedo therein the oilfield based on the method $6 \mathrm{~S}+$ Liang (2000). The research indicates, with the determination of processed values, which areas of oil exploration to the analyzed time, present significant change rates, with a tendency to increase in reflectance and temperature associated with albedo changes, as well as other areas of renewable energy exploration.
\end{abstract}

\section{INTRODUCTION}

The present research is based on the initial analysis of albedo as a relevant factor to energy balance, in earth surface related to 101 onshore production fields, that exist in the limits of Rio Grande do Norte State - Brazil.

Potiguar Basin has a total area of around $49.000 \mathrm{~km}^{2}$, of which $27.000 \mathrm{~km}^{2}$ are offshore and 22.000 onshore, divided between $\mathrm{CE}$ and $\mathrm{RN}$ states. Currently, this basin has been considered the biggest field of exploration in Brazil, in RN state it has an estimated area of $16.903,9 \mathrm{~km}^{2}$, it represents $34,5 \%$ of the total area. (Brazil - AnP, 2014)

Based on the need of observing about the oscillation wether conditions and related systems, index albedo control is necessary because it is a very significant reflectance index of solar radiation. Index albedo focus of interpretation is done in a kind of superficial scale of atmosphere and albedo index of surface.

The Potiguar Basin is located at a semiarid climate region with a severe semiarid subclassification in the center of this climate region, except in the area between coast zone and savanna, the weather is dry and hot, with temperatures over $25^{\circ} \mathrm{C}$ and rainfall annual measures lower than $600 \mathrm{~mm}$. The natural desertification process is present in this region and it has been changed by anthropic action (ANDRADE, 1973, p. 153).

Oil exploration in Potiguar Basin has origin in 50's, in twentieth century ant it had greatly grown, by the time new fields were discovered along the way, and new technologies in exploration were in the same sense, it turned possible oil extraction and natural gas extraction onshore in all 7.071 oil wells in the State (AnP, 2014).

Beside that and according to the Report of Energy Reserch Company - Brasil, EPE (2013) another forms of energy are explored in the State of RN, in a significant way, such as wood, eletric, (thermo and wind power) and biomass of sugar cane.

The albedo index is a concept that is associated to reflectance of solar radiation through the atmosphere and surface, where around $30 \%$ of radiation is reflected back to space, it is done mainly through short waves. It is considered an important sign about global climate changes.

In what is related to local and regional weather conditions, the superficial albedo index is a meaningful variable in the analysis when comparing to other ones (temperature, humidity, precipitation, evaporation / evapotranspiration). The main modulatory of atmospheric and superficial albedo is the cloud cover associated to atmospheric aerosol composition and the amount of solar rays, according to area location in analysis. (VEISSID, PEREIRA, 2000; FADIGAS, 2006; GOLDENBERG, 2007).

On the field of study's reality, the superficial albedo index changes that originated from exploration of biomasses (deforestation), desertification process, besides changes in the atmospheric composition due to the introduction of aerosols and gases from biomass burning, all of those factors are an important tool to the atmosphere energetic balance. (ECK et al., 1998; GALDINO, 2003)

Considering natural aspects related to savanna biome, that form almost total area of Potiguar Basin onshore, in the semiarid, albedo index represent an important variable to be observed, to evaluate a real climate evolution, taking into account natural structure and other relation in the anthrop actions, that occurs in that area.

Intending a comparative analysis, it was made an investigation based on $6 \mathrm{~S}$ method associated with correction rates for albedo calculation defined by Liang (2000), and data superficial reflectance established by applying the method GEOBIA (GEOGRAPHIC-Object-Based Image Analysis, 2014), both by ArGis 10 software. The results point towards a 
wider and detailed description of surface reflectance index through GEOBIA method, considering that all spectrum bands available in Landsat 8 were used in the analysis.

\section{2 . APPLIED METHODOLOGY}

Using remote sensing techniques and SIG, the arising data that were necessary to observe superficial albedo levels at Potiguar Basin were based on images from Landsat 8 satellite that came from USGS, through OLI sensors (Operational Land Imager) sensors and TIRS (Thermal Infrared Sensor) (USGS, 2013).

Five scenes were used to cover all the area we analyzed 216/063(159), 216/064(191), 215/063 (152), 215/064(152) e 214/064(161). The dates were defined taking into account time proximity to measurement period of aphelion of July, 2013, and we chose the scenes where less cover cloud $(<7 \%)$, we follow the tendency work, quoted by Roy, et. all (2014).

In the absence of 214/064 images of the scene with the cloud cover within the set margin of error, and there is no oil exploration field in this area is less than $5 \%$, the eastern end of the study area, the data in this scenario We were not used into account in the statistical analysis.

The outdoor work we had done allowed us to identify geo-reference points to have information spatial exact points for granted, they were associated to WGS- 84 projection system, and it had also granted the biggest precision of about $7,64 \mathrm{~m}$ to images in analysis with a kind of resolution of $14,96 \times 14,96 \mathrm{~m}$ per pixel. We used data from DBOPE (Data bank of Oil Production and Exploration), (BDEP in Brazil), associated to those images.

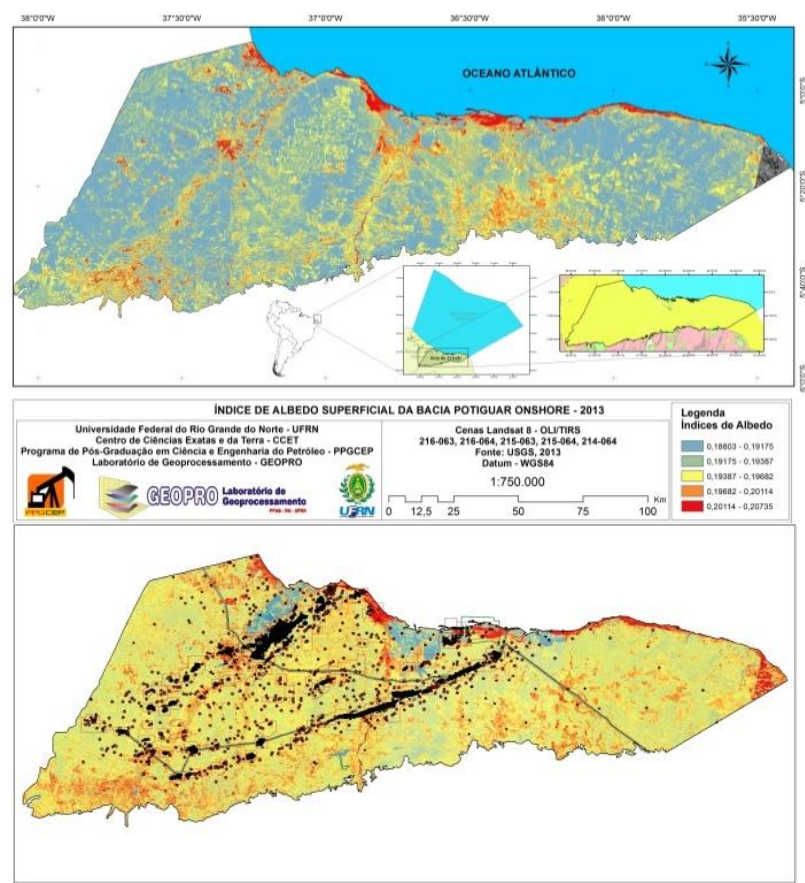

Figure 1. Image of area under analysis. Field location, wells and gas pipelines at Potiguar Basin - PB (BDEP, 2013).

Taking into account the composition of combined scenes, this is: RGB-I (R-6, G-234, B-53, I-7), it was possible to detach different structures of vegetation, explored areas, exposed soil, soil variation, hydrographic reserves and so many other forms of human occupation (Figure 2)
These information easy the reading comprehension of oil exploration area, as well as the comprehension of natural processes of high levels of reflectance.
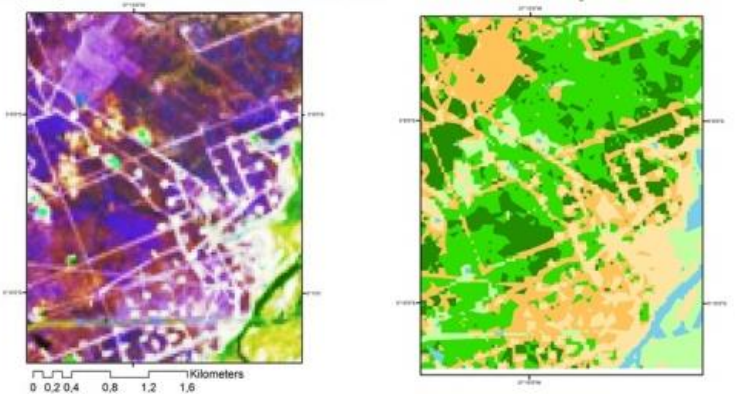

Figure 2. Composition of Images Landsat 8 (RGB-I) (left); and Classification NS from Landsat 8 Scene - 216-063(152/2013) (right).

We had still used information from high levels resolution images as complementary resources, images from satellites Rapideye e Topodata (MMA, 2014), we wanted to check how images were classified. Taking into account these basic information, we applied systems correction of atmosphere and reflectance analysis: the first one the $6 \mathrm{~S}$ (Vermont, et all, 2006) associated to another one proposed by Liang (2000) to albedo. We also used Geobia tool (GEOgraphic-Object-Based Image Analysis, 2014) through the software ArcGis 10 to analyze the medium of surface temperature and reflectance.

Through of Geobia Method, it was possible to do a panoramic reading of all reflectance degree that comes from Potiguar Basin surface, in a regional perspective. In the analysis, the variation through comparative analyzes among preserved areas and another activities developed there.

The method is based on the calculation of reflectance with atmosphere correction:

$\mathrm{R}_{\text {earth }}=\mathrm{R}_{\text {sat }}-\left(\mathrm{R}_{\text {scatter }}-0.01\right)$

Where:

$\mathrm{R}_{\text {earth }}$ : Reflectance of earth`s surface

$\mathrm{R}_{\text {sat }}$ : Reflectance of ToA

$R_{\text {sat }}=\frac{(D N-0.0002)-1}{\cos S Z}$

Where:

DN = Digital Number;

$\cos \mathrm{SZ}=$ cosine of $90^{\circ}$ - degree of solar elevation;

$\mathrm{R}_{\text {scatter }}$ : Reflectance scattered in the atmosphere

$R_{\text {scatter }}=\frac{\left(D N_{\min }-0.0002\right)-1}{\cos S Z}$

Where:

$\mathrm{DN}_{\text {min }}=$ minimum value of $\mathrm{DN}$;

$\cos \mathrm{SZ}=$ cosine of $90^{\circ}-$ degree of solar elevation;

Considering the use of correction system 6S (ANTUNES et al, 2014, p. 03; VERMOTE, 2006) we applied band corrections $2,3,4,5,6$ and 7, it was divided into three following levels: 2, 3, 4 (visible), 5 (infra red low), 6 e 7 (infra red medium).

It is important to point out that the observation in this method is based on the following variables: solar angle, zenithal angle, sun-earth distance, aerossol cover and atmosphere model. 
The atmosphere correction was individually done, by bands, and it had as consequences a high level of interpretation though three steps: calibration and radiance, atmosphere correction (ToA), and finally surface albedo measurement through of method Liang (2000).

Calibration and radiance:

$L_{\lambda}=1+\frac{L_{\max }-L_{\min }}{Q_{\text {cal } \max }-Q_{\text {calmin }}}\left(Q_{\text {calmax }}-Q_{\text {calmin }}\right)+L_{\text {min }}$

Where:

$L_{\lambda}:$ Radiance Value

$\mathrm{L}_{\max }$ : Maximun value radiance (W/Ester-radiano/ $/ \mathrm{m}^{-2} / \mu \mathrm{m}$ )

$L_{\text {min }}$ : Minimun Value Radiance (W/Ester-radiano $/ \mathrm{m}^{-2} / \mu \mathrm{m}$ )

$Q_{\text {calmax }}$ : Maximum value of grey levels used in quantifying data

$Q_{\text {calmin }}$ : Minimum value of grey levels used in quantifying data.

Atmosphere Correction

$\rho_{a p}=\frac{\pi x L_{\lambda x d^{2}}}{E_{\text {sol } x \cos \theta_{s}}}$

Where:

$\pi$ : solid angles in steradian.

$L_{\lambda}$ : Radiance Value;

$\mathrm{d}$ : distance sun-earth in astronomic units (AU);

$\mathrm{E}_{\mathrm{sol}}=$ Solar irradiance on one of the bands in $\mathrm{W} / \mathrm{m}^{-2} / \mu \mathrm{m}$;

After atmosphere correction, OLI sensor bands analyzed were underwent to the calculation of superficial albedo, it was based on method adaptation proposed by Liang (2000, p. 227) to the sensor ETM+ to OLI sensor, but it was done observing short wave adaptation and visible band.

Superficial Albedo:

$\alpha^{O L I}=\left(0.356 \alpha_{2}+0.317 \alpha_{3}+0.130 \alpha_{4}+0.373 \alpha_{5}+\right.$ $\left.0.085 \alpha_{6}+0.072 \alpha_{7}\right)-0.0018[6]$

Where:

$\alpha^{O L I}=$ Sensor Operational Land Image - Landsat 8, adapted from a relation among the bands sensor ETM+; 0,356 $\alpha_{2}$ : Specific value of band calibration.

After composition, classification and ToA albedo analysis, ToA and superficial we did a comparative analysis through the global albedo table proposed by Otterman (1977), where we verify the relationship between natural conditions that induce natural albedo in that area and changes caused by oil fields under our analysis.

\begin{tabular}{lr}
\multicolumn{1}{c}{ Kind of surface } & Albedo \\
\hline $\begin{array}{l}\text { Stable snow cover in high latitudes }\left(>60^{\circ} \text { of }\right. \\
\text { latitude ) }\end{array}$ & 0,80 \\
\hline Stable snow cover in medium latitudes & 0,70 \\
\hline Unstable snow cover in the Autumn & 0,50 \\
\hline Forest covered by stable snow & 0,45 \\
\hline $\begin{array}{l}\text { Forest covered by unstable snow in the } \\
\text { Autumn }\end{array}$ & 0,30 \\
\hline Desert & $\mathbf{0 , 2 8}$ \\
\hline $\begin{array}{l}\text { Forest with falling leaves during a dry } \\
\text { period, cerrado and semi desert. }\end{array}$ & $\mathbf{0 , 2 4}$ \\
\hline
\end{tabular}

\begin{tabular}{lc}
\hline $\begin{array}{l}\text { Forest falling leaves during a rainy } \\
\text { period, thick and semi desert. }\end{array}$ & $\mathbf{0 , 1 8}$ \\
\hline $\begin{array}{l}\text { Estep or decidua forest (temperature over } \\
10^{\circ} \text { in the Spring before snow covering). }\end{array}$ & 0,18 \\
\hline Tundra without snow covering. & 0,18 \\
\hline Acicular Forest (temperatures over $10^{\circ}$ ). & 0,14 \\
\hline Steep and forest during transition period. & 0,13 \\
\hline
\end{tabular}

Tabel 1. Medium albedo values, according to Otterman, 1976.

\section{RESULTS AND DISCUSSION}

If we consider the first results obtained through the application of GeoBia and $6 \mathrm{~S}+$ Liang (2000) techniques, it is possible to observe the following considerations:

The area under analysis has a level of reflectance based on superficial albedo associated to what is estimated by Otterman (1977), in the item "forest falling leaves during a dry period, thick and semi desert" with albedo estimated at 0,18 .

Considering that albedo index in desert zones at $(0,28)$, the area under analysis is in an inferior level, so if we consider data band VIS/IR-P/IR-M $(0,1571)$ and nearer to those areas in relation to VIS/IR-P $(0,2066)$. This fact can be associated to natural conditions level and its chemical-physical properties after the period of higher rain period in the region (jan-jun).

By the establishment of controlled points: preserved vegetation, cover clouds, shadows of clouds, saline deposit and urban areas, it was possible to analyze in a comparative way albedo index related to these areas but with different changes tendencies.

At preserved caatinga region there is a tendency of lower rates of albedo, they are shown in a variation from 0,10 to 0,15. According to Otterman (1977), the medium of albedo related to forests in semiarid tropical areas is approximately about 0,14 (Figure 4).

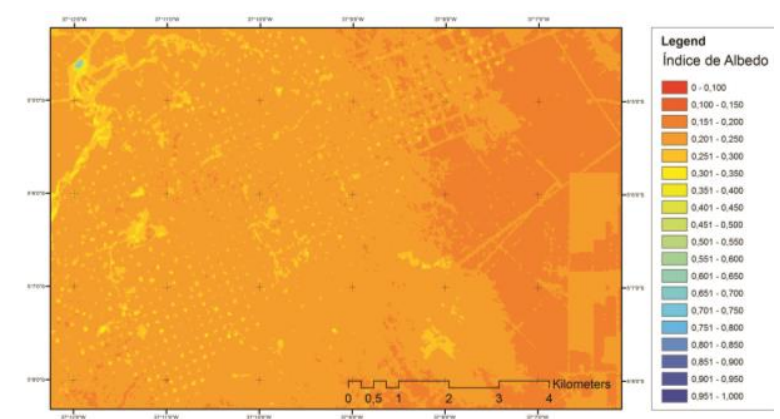

Figure 3: Superficial reflectance values, through Geobia Method from part of the CAM field.

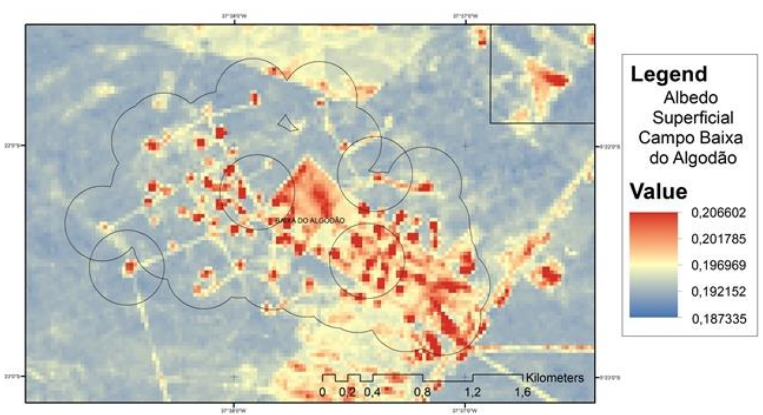

Figure 4. Estimated superficial albedo by the method 6S \& Liang (2000), at BAL field. 
After the selection of fields whose influence presents regional potential of climatic alteration $\left(>3000 \mathrm{~m}^{2}\right.$ - based in used scale 1:750.000), it was done a classification of data in relation to total area of the field and the area of direct influence of exploration (wells, gas pipelines, preprocessing and processing).

These data indicate that many fields presents altered index by presenting parallel activities in its area (agriculture, biomass exploration, urban areas and visible salt exploration in blue area of the figure 03) that alter the perspective in analysis by field, because of this was adopted the selection with $300 \mathrm{~m}$ area just around of the activities of direct exploration of oil and natural gas.

\begin{tabular}{cccccc}
\hline $\mathbf{N}^{\mathbf{o}}$ & Code & Min_EP & Max_EP & Mean_EP & St_Dev_EP \\
\hline 1 & ARG & 0,053504 & 0,645346 & 0,258199 & 0,069645 \\
\hline 2 & BAL & 0,043490 & 0,385675 & 0,122982 & 0,031405 \\
\hline 3 & BEM & 0,104291 & 0,377356 & 0,161016 & 0,049158 \\
\hline 4 & BVS & 0,098585 & 0,356945 & 0,154126 & 0,050452 \\
\hline 5 & BR & 0,070176 & 0,441374 & 0,176264 & 0,051777 \\
\hline 6 & CAM & 0,010811 & 0,538074 & 0,162068 & 0,064278 \\
\hline 7 & ET & 0,002076 & 0,580894 & 0,190535 & 0,061223 \\
\hline 8 & FMQ & 0,079314 & 0,313120 & 0,112323 & 0,024831 \\
\hline 9 & FP & 0,111341 & 0,672718 & 0,253326 & 0,067567 \\
\hline 10 & GMR & 0,160705 & 0,655301 & 0,215433 & 0,044648 \\
\hline 11 & LV & 0,029691 & 0,407038 & 0,143798 & 0,043619 \\
\hline 12 & LOR & 0,061638 & 0,441435 & 0,131587 & 0,039384 \\
\hline 13 & MAG & 0,157249 & 0,661390 & 0,224118 & 0,049708 \\
\hline 14 & MOR & 0,104310 & 0,325440 & 0,125611 & 0,028852 \\
\hline 15 & PJ & 0,082404 & 0,323103 & 0,119520 & 0,024016 \\
\hline 16 & PML & 0,100714 & 0,609326 & 0,193112 & 0,075072 \\
\hline 17 & RE & 0,106152 & 0,491453 & 0,145318 & 0,037128 \\
\hline 18 & REP & 0,100501 & 0,349091 & 0,142265 & 0,042173 \\
\hline 19 & RFQ & 0,043400 & 0,354268 & 0,121550 & 0,028443 \\
\hline 20 & SE & 0,097460 & 0,428327 & 0,158731 & 0,044776 \\
\hline 21 & UPN & 0,080534 & 0,366530 & 0,156513 & 0,033263 \\
\hline 22 & SCR & 0,017223 & 0,701261 & 0,195982 & 0,105308 \\
\hline 23 & SER & 0,059948 & 0,607719 & 0,368373 & 0,143655 \\
\hline 24 & MA & 0,029696 & 0,640282 & 0,302815 & 0,198782 \\
\hline 25 & PITI & 0,018971 & 0,617492 & 0,256322 & 0,110869 \\
\hline & & & & & \\
\hline 1 & & & \\
\hline
\end{tabular}

Table 2. Field General Reflectance Index with regional influence (>3000 $\left.\mathrm{m}^{2}\right)$.

The observation of rates band by band provided the integration of bands of visible electromagnetic spectrum, near infra-red and mid infra-red, what demonstrate that bands of short frequency presents one indicative significant tendency of values of albedo in the area under analysis, providing a quantification more precise of analyzed areas.

Through the quantification with the use of statistic free software ( $\mathrm{R}$ - The R Foudation for Statical Computing - 2015) was possible to analyze the general table of PB (Potiguar Basin), with covering of about $97 \%$ of total area, it was exempt only one part of extreme east where there is no any oil exploration and whose scenario presents clouds covering above average of other scenarios.

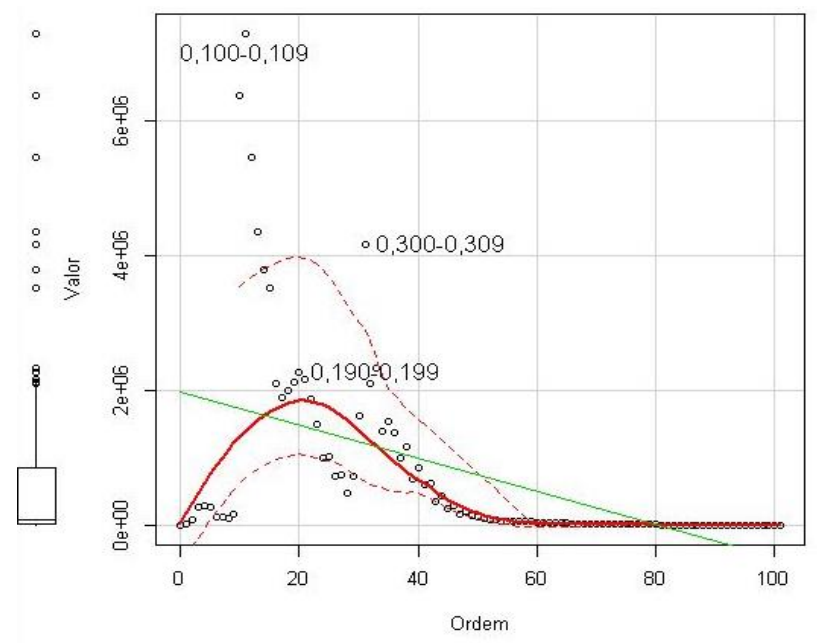

Figure 5. Scatterplot general reflectance data determination of Bacia Potiguar.

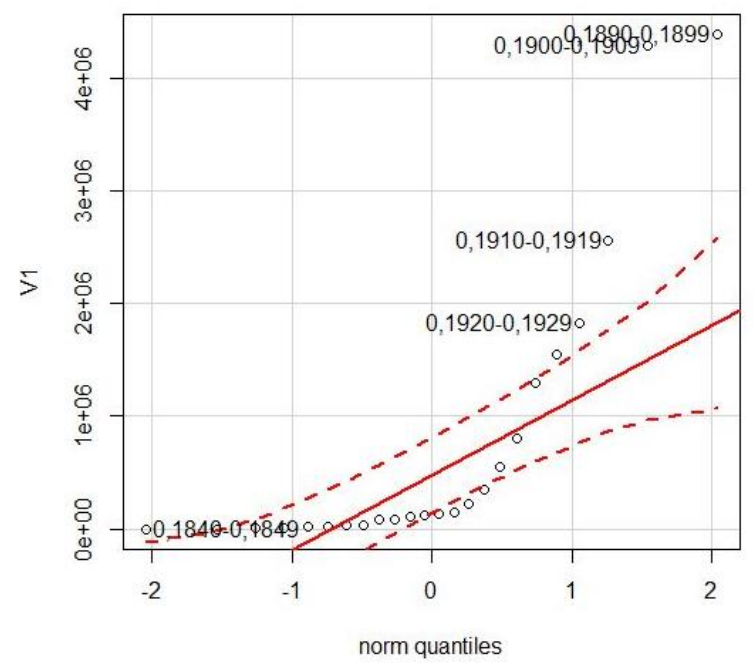

Figure 6. Norm Quantiles of superficial index albedo analysis, highligting the values 0,1900-0,1909 and 0,1890-0,1899 at Potiguar Basin.

We identify 11 oil exploration fields with index that is considered a high level, above average $(>0,16)$, those values are above average of preserved vegetation areas and they're of lower levels in the areas of high index of albedo and natural temperatures.

Those data are not really concluded in their statistic treatment, but it searches to show a kind of general profile, and at the same time it tries to identify oil fields of higher changes influence, that are under observation. A significant order of reflectance in a band from 0,1 to 0,3 fits in data that can be found in the oil exploration area, but the areas highly depends on geosystem where they are located. So, it is necessary a selection and classification of those sub-divisions.

We also applied the analysis of superficial temperature, it is an important aspect in climate analysis, because this way it was possible to see the relationship among rates of albedo, values of superficial reflectance in a wide spectrum and the own changes of temperatures. 


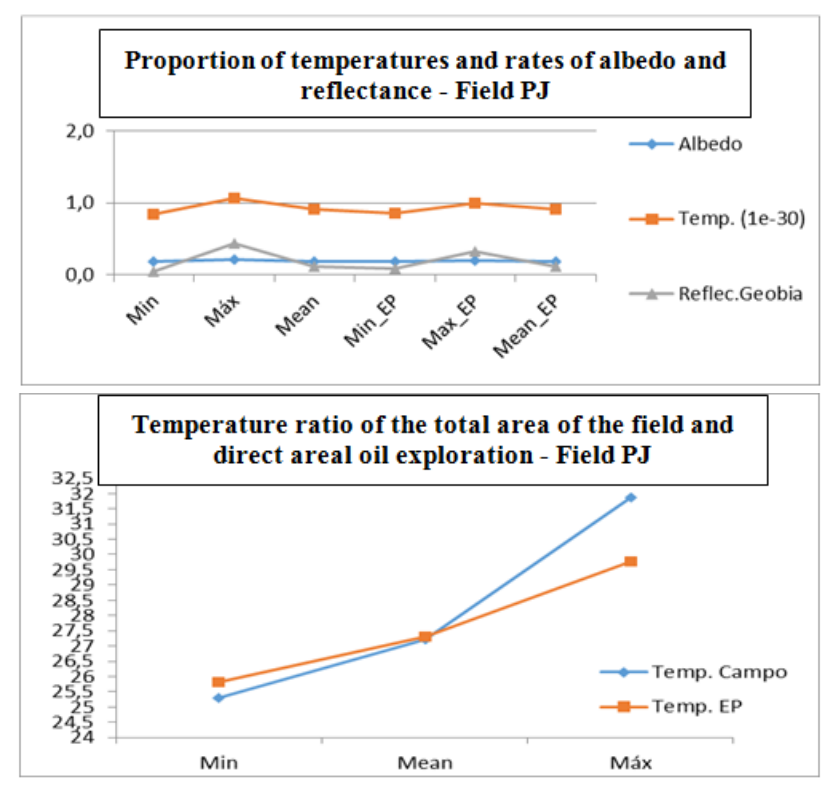

Figure 7. Graphics proportion between temperatures, albedo and relfectance - PJ Field; Relation between the total area of the field and the direct area of exploration - PJ Field.

As we can observe at the figure 7 , variation of temperature are more related to variation on reflectance in general, maximum temperature variation are not direct associated to oil exploration areas, i.e. direct to areas of oil wells or gas pipeline used as reference.

\section{CONCLUSIONS}

The results show that the oil area under analysis presents variations on the superficial albedo index of low significance, with the analysis in course, related to the associated changes on the anthropic activities on the region (farming, urban areas, and the exploration of other energy resources).

On overall perspective in the use of energy exploration activities, considered renewable and non-renewable energy provided changes in the superficial aspects of albedo and superficial temperature jointly in the area under analysis in this research.

Potiguar Basin has natural areas with high levels of reflectance and albedo, located in areas of dune fields, crystalline outcrops and soils with low rate of absorption associated with dryland vegetation due to semi aridity of the region, taking into account it has low potential for solar radiation absorption. Great dune fields on the coast naturally presents high levels of albedo index and temperature without direct anthropic influence. Rocky sandstone outcrops also presents positive variations in its natural aspect.

When we analyze temperature alteration in a comparative way we can see that they are proportionally related to reflectance alterations by Geobia method than to albedo index, however, this relation happens in a more local-regional scope. Meanwhile, the albedo refers to a more regional-global scope.

Those variations are important to understand the final frame of identification in the more affected areas, and those that need a special attention in order to avoid future irreversible degradation scenes.

The relations among the geosystemic structures that compose the areas under study should be considered in order to observe the causes of the alterations on the superficial albedo indexes in exploration areas.

\section{ACKNOWLEGEMENTS}

We are thankful to all support by Professors of PPGCEP/UFRN as well as Academic Community from GEOPRO/UFRN, especially to $\mathrm{PhD}$ Professor Venerando Eustáquio Amaro.

\section{REFERENCES}

ANDRADE, M. C., 1973. The semiard coastal region of northeastern Brasil. In: AMIRAN. D. H. K.; WILSON. A. W. Coastal Deserts: the natural and human environments. The University of Arizona Press, Tucson..

ANTUNES, M. A. H.; FREIRE, R. M. B.; BOTELHO, A. S.; TONIOLLI, L. H. Correções atmosféricas de imagens de satélites utilizando o modelo 6S, 2014. http://www.research gate.net/publication/255635015_correes_atmosfricas_de_image ns_de_satlites_utilizando_o_modelo_6s.

BRASIL, MME. Ministério das Minas e Energia, EPE. Empresa de Pesquisa Energética., 2013. Balanço Energético Nacional 2013: ano base 2012. Rio de Janeiro.

BRASIL. ANP. BDEP, 2014. Banco de Dados de Exploração e Produção. http://app.anp.gov.br/webmaps

ECK, T.F., BRENT, H. N., SHUTSKER, I. \&SETZER, A., 1998. Measurements of irradiance attenuation and estimation of aerosol single scattering albedo for biomass burning aerosols in Amazonia. Journal Geophys. Res. 103 (D24): p.865878. 1998.

FADIGAS, E. A. F. A. ; REIS, L. B. ; CARVALHO, C. E., 2005. Energia, Recursos Naturais e a Prática do Desenvolvimento Sustentável. Manole, São Paulo.

GALDINO, C. A. B., 2003. Passivo ambiental e o setor de exploração de petróleo em terra: abordagem teórica e percepção institucional dos impactos ambientais gerados pela atividade. Dissertação do Programa de Engenharia de Produção da Universidade Federal do Rio Grande do Norte. Natal.

GOLDENBERG, J. ; LUCON, O., 2007 Energia, Meio Ambiente e Desenvolvimento. Edusp, São Paulo.

IGAC - Instituto Geografico Agustin Codazzi. Descripción y correccion de produtos Landsat 8: Landsat Data Continuity Mission. Versión 1.0. Bogotá: Colômbia, 2013.

OTTERMAN, J. Anthropogenic impact on the albedo of the earth., 1977. In: Climatic Change 1. Dordrecht, pp. 137155.

LIANG, S., 2000. Narrowband to broad band conversions of land surface albedo - I algoritms. Remote Sensing of Environment, nov. pp. 213-238

MMA - MINISTÉRIO DO MEIO AMBIENTE. 2014. Geocatálogo. http://www.geocatalogomma.com.br/ 
ROY, D. P., WULDER, M. A., LOVELAND, T. R., ET ALL "Landsat-8: Science and product vision for terrestrial global change research" 2014. Papers in Natural resources. PAPER 459. http://digitalcommons.unl.edu/natrespapers/459.

USGS. Geological Survey., 2013. Satellit Scenes of Landsat-8. http://earthexplorer.usgs.gov/.

UNIVERSITY OF CALGARY., 2014. GEOgraphic-ObjectBased Image Analysis. www.ucalgary.ca/f3gisci/GEOBIA

VEISSID, N.; PEREIRA, E. B., 2000. Estimativa do albedo planetário empregando dados do experimento célula solar do satélite brasileiro SCD2. Brazilian Journal of Geophysics, Vol. 18(1), p. 26.

VERMOTE E, TANRÉ D., J. L. DEUZÉ, M. HERMAN, J. J. MORCRETTE, KOTCHENOVA S. Y., 2006. Second Simulation Of The Satellite Signal In The Solar Spectrum, 6s: An Overview. 6S User Guide Version 3. 